\title{
Human Orthobunyavirus Infections, Tefé, Amazonas, Brazil
}

March 22, $2018 \cdot$ Research Article

\section{Citation}

Naveca FG, Nascimento VA, Souza VC, Figueiredo RMd. Human Orthobunyavirus Infections, Tefé, Amazonas, Brazil. PLOS Currents Outbreaks. 2018 Mar 22 . Edition 1. doi:

10.1371/currents.outbreaks.7d65e5eb6ef75664da68905c5582f7f7.

\section{Authors}

Felipe Gomes Naveca

Laboratório de Ecologia de Doenças Transmissíveis na Amazônia, Instituto Leônidas e Maria Deane - Fiocruz Amazônia, Manaus, Amazonas, Brazil.

Valdinete Alves Nascimento

Laboratório de Ecologia de Doenças Transmissíveis na Amazônia, Instituto Leônidas e Maria Deane - Fiocruz Amazônia, Manaus, Amazonas, Brazil.

\section{Victor Costa Souza}

Laboratório de Ecologia de Doenças Transmissíveis na Amazônia, Instituto Leônidas e Maria Deane - Fiocruz Amazônia, Manaus, Amazonas, Brazil.

Regina M.P. de Figueiredo

Gerência de Virologia, Fundação de Medicina Tropical Doutor Heitor Vieira Dourado, Manaus, Amazonas, Brazil.

\section{Abstract}

Introduction: Several orthobunyaviruses are important arthropod-borne pathogens, responsible for a variety of diseases in humans, from acute febrile illness to encephalitis.

Methods: We collected serum samples from a series of dengue suspected cases in Tefé, a mid-size city located in the interior of the Amazonas state, Brazil. Viral RNA extraction was performed, and specimens were tested for dengue virus using RT-PCR. Thirty dengue negative samples were further tested for Mayaro virus (MAYV) and Oropouche virus (OROV) using an RT-qPCR protocol previously described. Positive samples were characterized by MegaBLAST analysis over the entire nucleotide collection of the main public databases, and also by maximum likelihood phylogenetic reconstruction of the $S$ genome segment.

Results: We detected nine OROV or OROV-like positive cases among 30 patients reporting fever and headache, as the most common symptoms. The closest nucleotide sequence returned from the MegaBLAST analysis belongs to an OROV isolated in Peru 2008. Moreover, all Tefé samples grouped in the same clade with the OROV reference sequence and other closely-related OROV-like viruses.

Discussion: Dengue viruses are still the most important arbovirus worldwide, causing hundreds of millions of infections every year. Nonetheless, other arboviruses like chikungunya virus, Zika virus, and yellow fever virus have emerged in the last few years and are now a public health concern in several countries. OROV is believed to have caused more than 500,000 febrile infections in Brazil over recent decades. Therefore, the 
results described in this study strengthen that this arbovirus, and its closely-related recombinants, should be under continuous surveillance, at least in the endemic countries of Latin America.

\section{REPORT}

Between April and June 2015, professionals of the health surveillance system at Tefé $\left(03^{\circ} 21^{\prime} 14^{\prime \prime} \mathrm{S} ; 64^{\circ} 42^{\prime}\right.$ $39 " \mathrm{~W}$ ), a mid-size city located in the interior of the Amazonas state, Brazil, collected serum samples from a series of dengue suspected cases. The specimens were obtained between the first and second day after symptom onset and sent to Fundação de Medicina Tropical - Dr. Heitor Vieira Dourado (FMT-HVD) at Manaus, Amazonas, Brazil for dengue virus (DENV) testing using RT-PCR ${ }^{1}$.

Thirty DENV negative samples were randomly selected and sent to Instituto Leônidas e Maria Deane (ILMD), Fiocruz Amazônia, to investigate other Amazonian endemic arboviruses ${ }^{2,3,4,5}$. At ILMD, samples were tested using a multiplexed reverse transcription real-time PCR protocol for Oropouche, and Oropouche-like viruses, (OROV, Peribunyaviridae family, genus Orthobunyavirus), targeting the $\mathrm{S}$ segment; as well as for Mayaro virus (MAYV, Togaviridae family, Alphavirus genus) aiming the NSP1 coding region ${ }^{6}$. All patients gave written informed consent, and the principal investigators anonymized the participants' data. The ethics committee of FMT-HVD approved the study under the registration number 700.915

We detected nine OROV or OROV-like positive cases (TF031; TF036; TF070; TF081; TF086; TF087; TF100; TF101; TF103), seven males and two females, with a mean age of 36.2 years (range $8-63$ ), living in either rural or urban areas of Tefé. Regarding the clinical symptoms, all nine patients reported fever and headache; two patients also reported myalgia and arthralgia and one showed retro-orbital pain. Therefore, these patients presented non-specific symptoms that could easily lead to dengue misdiagnosis, if no specific laboratory testing were applied.

To further confirm these results, all nine samples were submitted to an RT-PCR protocol targeting the $S$ segment of OROV/OROV-like viruses using primers OROV_S_134F 5'- CGGACAAGTGCTCAATGCTG -3' and OROV_S_734F 5'- GTCAATTCCGAATTGGCGCA - 3', generating a $601 \mathrm{bp}$ amplicon. These products were used for capillary nucleotide sequencing in an ABI3130 genetic analyzer, installed at the ILMD genomics platform. After removal of the primers, the final 558bp sequence for each sample was used for a multiple alignment with MAFFT ${ }^{7}$, embedded in Geneious Software 10.2.2 ${ }^{8}$. The orthobunyavirus sequences obtained in this study were highly conserved among them, as should be expected for any arbovirus samples collected from the same area, in a small-time frame. Only one nucleotide variation was observed in the sample TF86, a silent mutation (Transversion: T / A) in position 386 related to the OROV reference sequence for segment $S$ NC_005777.

We also conducted a BLAST analysis ${ }^{9}$ over the consensus nucleotide sequence, using the MegaBLAST algorithm ${ }^{10}$. Only orthobunyavirus sequences were retrieved among the first 100 hits with the higher score and lower E-values. The closest nucleotide sequence returned from the MegaBlast analysis belongs to an Oropouche virus isolated in Peru 2008 (strain TVP-19256/IQE-7894 - KP795086) sharing 98\% similarity, with $545 / 558$ identical sites.

Recently, the International Committee on Taxonomy of Viruses (ICTV) made several changes in virus taxonomy, comprising the creation of the Bunyavirales order. This new order contains eight new viral families (Feraviridae; Fimoviridae; Hantaviridae; Jonviridae; Nairoviridae; Phasmaviridae; Phenuiviridae and Tospoviridae) and one family that was renamed: Peribunyaviridae, formerly Bunyaviridae. Two genera are included in the Peribunyaviridae family, genus Herbevirus and genus Orthobunyavirus ${ }^{11}$.

Currently, ICTV recognizes 48 species in the Orthobunyavirus genus (ICTV Master Species List 2016 v1.3 available at https://talk.ictvonline.org/files/master-species-lists $/ \mathrm{m} / \mathrm{ms} / / 6776 /$ download). According to the ICTV Virus Metadata Repository (version November 8, 2017, available at https://talk.ictvonline.org/taxonomy/vmr/m/vmr-file-repository/7019), among those 48 orthobunyaviruses species, 35 have sequence data deposited in GenBank regarding the S segment. Thus, we used the PhyML 
software ${ }^{12}$ embedded in Geneious Software 10.2.2, for maximum likelihood phylogenetic reconstruction with the ICTV recognized orthobunyavirus species; our data from the Tefé samples and six OROV-like viruses marked with a star $\left({ }^{*}\right)$. The phylogenetic tree was edited with FigTree v1.4.3, available at http://tree.bio.ed.ac.uk/software/figtree/.

All Tefé samples grouped in the same clade with the species Oropouche orthobunyavirus (RefSeq NC_005777) and the closely-related OROV-like viruses (Utinga virus, Utive virus, Madre de Dios virus, Iquitos virus and Perdões virus). One exception was observed for the Facey's Paddock virus, another OROV-like virus isolated initially in Australia 1974, which grouped with the Manzanilla orthobunyavirus isolated in Vietnam, 2004 (Fig 1). 


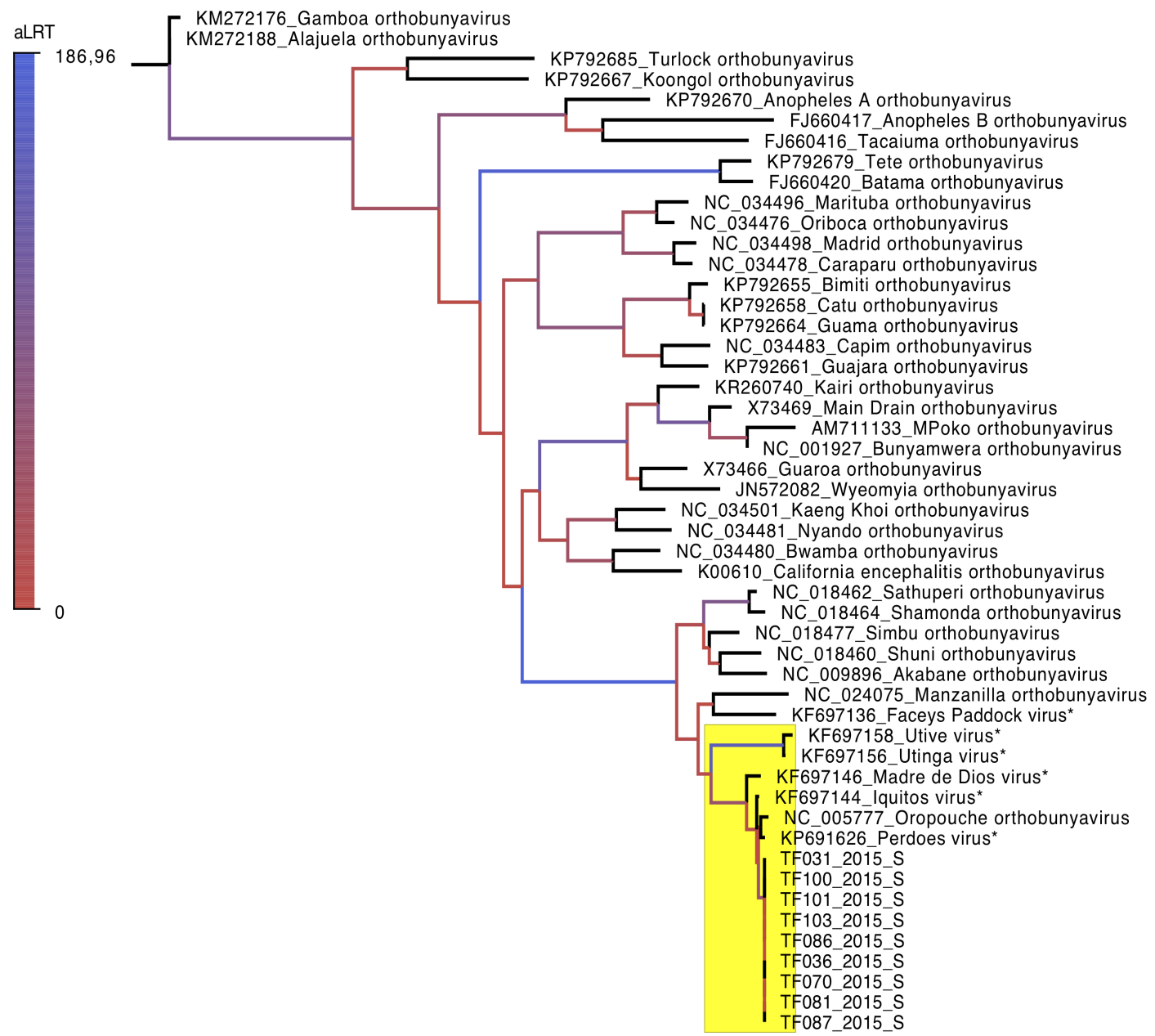

Fig. 1: Maximum likelihood tree of the genomic $S$ segment of orthobunyaviruses.

All ICTV recognized orthobunyavirus species with available genomic data for the $S$ segment were used for phylogenetic reconstruction, together with Tefé samples and other OROV-like viruses. The clade containing the Tefé samples, grouped with the species Oropouche orthobunyavirus, and the closely-related OROV-like viruses, is highlighted in yellow. Branches are colored according to the aLRT support. 
Annually, dengue viruses cause hundreds of millions of febrile infections, of widely varying intensity, in humans throughout the tropics and sub-tropics. Oropouche fever, caused by Oropouche virus (OROV) is less well studied but is believed to have caused more than 500,000 febrile infections in Brazil over recent decades ${ }^{13}$. Such cases could easily be clinically misdiagnosed for dengue infections. Moreover, OROV is a typical orthobunyavirus possessing a triple-segmented RNA genome which readily undergoes genetic reassortment with related orthobunyaviruses ${ }^{14}$, potentially resulting in genetically distinct recombinant variants of OROV $15,16,17,18$. Consequently, further molecular studies are currently being undertaken to determine the extent to which infections due to OROV and/or OROV-related recombinants (for example, Perdões virus), are being mistakenly clinically diagnosed as being caused by dengue viruses.

\section{Funding}

FGN is funded by Fundação de Amparo à Pesquisa do Estado do Amazonas - FAPEAM (www.fapeam.am.gov.br, call 001/2013 - PPSUS / 062.00656/2014 and call 001/2014 - PROEP / 062.01939/2014); Conselho Nacional de Desenvolvimento Científico e Tecnológico (http://www.cnpq.br, grant 440856/2016-7) and Coordenação de Aperfeiçoamento de Pessoal de Nível Superior (http://www.capes.gov.br, grants 88881.130825/2016-01 and 88887.130823/2016-00) call MCTIC/FNDCT CNPq / MEC-CAPES/ MS-Decit 14/2016 - Prevenção e Combate ao vírus Zika. RMPF is funded by Fundação de Amparo à Pesquisa do Estado do Amazonas - FAPEAM (www.fapeam.am.gov.br, call 001/2013 - PPSUS). The funders had no role in study design, data collection and analysis, decision to publish, or preparation of the manuscript.

\section{Competing Interests}

The authors have declared that no competing interests exist.

\section{Data Availability}

All partial S segment orthobunyavirus sequences are available as a FASTA file at https://doi.org/10.6084/m9.figshare.5458342.v1/.

\section{Corresponding Authors}

Dr. Felipe Gomes Naveca (felipe.naveca@fiocruz.br) and Dr. Regina Maria Pinto de Figueiredo (figueiredormp@yahoo.com.br).

\section{Acknowledgements}

The authors are thankful to the Programa de Desenvolvimento Tecnológico em Insumos para a Saúde PDTIS-FIOCRUZ for the use of the Real-Time PCR and nucleotide sequencing facilities at ILMD. We are also grateful to Maria Itelvina Rodrigues de Souza, Anete Jane Cavalcante da Silva, Valcinei Silva Amorim from the Secretaria Municipal de Saúde de Tefé, Amazonas, Brazil, and Wellyngton do Nascimento Lopes for their technical support during the development of this work. We are grateful to Dr. Aileen Chang, from George Washington University, for English reviewing of the manuscript.

\section{References}

1. de Morais Bronzoni RV, Baleotti FG, Ribeiro Nogueira RM, Nunes M, Moraes Figueiredo LT. Duplex reverse transcription-PCR followed by nested PCR assays for detection and identification of Brazilian alphaviruses and flaviviruses. J Clin Microbiol. 2005 Feb;43(2):696-702. PubMed PMID:15695666. 
2. Figueiredo LT. Emergent arboviruses in Brazil. Rev Soc Bras Med Trop. 2007 Mar-Apr;40(2):224-9. PubMed PMID:17568894.

3. Vasconcelos PF, Calisher CH. Emergence of Human Arboviral Diseases in the Americas, 2000-2016. Vector Borne Zoonotic Dis. 2016 May;16(5):295-301. PubMed PMID:26991057.

4. Mourão MP, Bastos Mde S, de Figueiredo RP, Gimaque JB, Galusso Edos S, Kramer VM, de Oliveira CM, Naveca FG, Figueiredo LT. Mayaro fever in the city of Manaus, Brazil, 2007-2008. Vector Borne Zoonotic Dis. 2012 Jan;12(1):42-6. PubMed PMID:21923266.

5. Bastos Mde S, Figueiredo LT, Naveca FG, Monte RL, Lessa N, Pinto de Figueiredo RM, Gimaque JB, Pivoto João G, Ramasawmy R, Mourão MP. Identification of Oropouche Orthobunyavirus in the cerebrospinal fluid of three patients in the Amazonas, Brazil. Am J Trop Med Hyg. 2012 Apr;86(4):732-5. PubMed PMID:22492162.

6. Naveca FG, Nascimento VAD, Souza VC, Nunes BTD, Rodrigues DSG, Vasconcelos PFDC. Multiplexed reverse transcription real-time polymerase chain reaction for simultaneous detection of Mayaro, Oropouche, and Oropouche-like viruses. Mem Inst Oswaldo Cruz. 2017 Jul;112(7):510-513. PubMed PMID:28591313.

7. Katoh K, Misawa K, Kuma K, Miyata T. MAFFT: a novel method for rapid multiple sequence alignment based on fast Fourier transform. Nucleic Acids Res. 2002 Jul 15;30(14):3059-66. PubMed PMID:12136088.

8. Kearse M, Moir R, Wilson A, Stones-Havas S, Cheung M, Sturrock S, Buxton S, Cooper A, Markowitz S, Duran C, Thierer T, Ashton B, Meintjes P, Drummond A. Geneious Basic: an integrated and extendable desktop software platform for the organization and analysis of sequence data. Bioinformatics. 2012 Jun 15;28(12):1647-9. PubMed PMID:22543367.

9. Altschul SF, Gish W, Miller W, Myers EW, Lipman DJ. Basic local alignment search tool. J Mol Biol. 1990 Oct 5;215(3):403-10. PubMed PMID:2231712.

10. Morgulis A, Coulouris G, Raytselis Y, Madden TL, Agarwala R, Schäffer AA. Database indexing for production MegaBLAST searches. Bioinformatics. 2008 Aug 15;24(16):1757-64. PubMed PMID:18567917.

11. Adams MJ, Lefkowitz EJ, King AMQ, Harrach B, Harrison RL, Knowles NJ, Kropinski AM, Krupovic M, Kuhn JH, Mushegian AR, Nibert M, Sabanadzovic S, Sanfaçon H, Siddell SG, Simmonds P, Varsani A, Zerbini FM, Gorbalenya AE, Davison AJ. Changes to taxonomy and the International Code of Virus Classification and Nomenclature ratified by the International Committee on Taxonomy of Viruses (2017). Arch Virol. 2017 Aug;162(8):2505-2538. PubMed PMID:28434098.

12. Guindon S, Dufayard JF, Lefort V, Anisimova M, Hordijk W, Gascuel O. New algorithms and methods to estimate maximum-likelihood phylogenies: assessing the performance of PhyML 3.0. Syst Biol. 2010 May;59(3):307-21. PubMed PMID:20525638.

13. Travassos da Rosa JF, de Souza WM, Pinheiro FP, Figueiredo ML, Cardoso JF, Acrani GO, Nunes MRT. Oropouche Virus: Clinical, Epidemiological, and Molecular Aspects of a Neglected Orthobunyavirus. Am J Trop Med Hyg. 2017 May;96(5):1019-1030. PubMed PMID:28167595.

14. Briese $\mathrm{T}$, Calisher $\mathrm{CH}$, Higgs $\mathrm{S}$. Viruses of the family Bunyaviridae: are all available isolates reassortants? Virology. 2013 Nov;446(1-2):207-16. PubMed PMID:24074583.

15. Saeed MF, Wang H, Suderman M, Beasley DW, Travassos da Rosa A, Li L, Shope RE, Tesh RB, Barrett AD. Jatobal virus is a reassortant containing the small RNA of Oropouche virus. Virus Res. 2001 Sep;77(1):2530. PubMed PMID:11451484.

16. Aguilar PV, Barrett AD, Saeed MF, Watts DM, Russell K, Guevara C, Ampuero JS, Suarez L, Cespedes M, Montgomery JM, Halsey ES, Kochel TJ. Iquitos virus: a novel reassortant Orthobunyavirus associated with human illness in Peru. PLoS Negl Trop Dis. 2011 Sep;5(9):e1315. PubMed PMID:21949892. 
17. Ladner JT, Savji N, Lofts L, Travassos da Rosa A, Wiley MR, Gestole MC, Rosen GE, Guzman H, Vasconcelos PF, Nunes MR, J Kochel T, Lipkin WI, Tesh RB, Palacios G. Genomic and phylogenetic characterization of viruses included in the Manzanilla and Oropouche species complexes of the genus Orthobunyavirus, family Bunyaviridae. J Gen Virol. 2014 May;95(Pt 5):1055-66. PubMed PMID:24558222.

18. Tilston-Lunel NL, Hughes J, Acrani GO, da Silva DE, Azevedo RS, Rodrigues SG, Vasconcelos PF, Nunes MR, Elliott RM. Genetic analysis of members of the species Oropouche virus and identification of a novel M segment sequence. J Gen Virol. 2015 Jul;96(Pt 7):1636-50. PubMed PMID:25735305. 